\section{"PREVALENCE AND PATTERN OF ANAEMIA IN CHILDREN BETWEEN 1-5 YEAR OLD CHILDREN: A HOSPITAL-BASED STUDY"}

KEY WORDS: Anemia, PreSchool Children, Prevalence, Under Five-Years-Old Children

\section{Dr. Gayathri D*}

Dr. M. Kulandaivel
Assistant Professor, Department Of Pediatrics, Sri Venkateshwaraa Medical College And Research Centre, Ariyur, Pondicherry. *Corresponding Author

Professor, Department Of Pediatrics, Sri Venkateshwaraa Medical College And Research Centre, Ariyur, Pondicherry.

Background: 'Anaemia' refers to a condition in which the hemoglobin content of the blood is lower than normal as a result of deficiency of one or more essential nutrients, heavy blood loss, parasitic infections and congenital hemolytic diseases. Anemia is a critical health concern because it affects growth and energy levels adversely. The present study was done to determine the prevalence, associated factors and pattern of anemia in under five-year-old children in a tertiary care teaching hospital. Methods: A prospective observational study was carried out among under five-year-old children admitted in the hospital for various medical illnesses. For the diagnosis of anemia, WHO criteria for haemoglobin $(\mathrm{Hb})$ threshold in different age group were used. Results: Total 112 anemic children were enrolled into the study. Children of age group of between 1-5 years were affected. A majority of the mother of anemic children had primary level of school education. More than half of the children belong to lower socioeconomic classes (Class IV + Class V). Nutritional deficiency was the single most important causative factor in the development of anemia. In our study the prevalence of anaemia was $75 \%$ with ranging from mild, moderate and severe. Conclusion: Nutritional deficiency, particularly, iron deficiency is the leading cause of anemia in the present study. This disorder can be primarily prevented by proper nutritional habits and adequate treatment.

\section{INTRODUCTION}

Anemia is a major health problem in worldwide. Because of the health and social economic problems the prevalence of anemia is higher in developing countries India. Children and pregnant women are the mostly vulnerable groups to anemia. 'Anemia' refers to a condition in which the hemoglobin content of the blood is lower than normal as a result of deficiency of one or more essential nutrients, ${ }^{[1]}$ heavy blood loss, parasitic infections and congenital hemolytic diseases. Anemia is a critical health concern because it affects growth and energy levels adversely. ${ }^{(2)}$

In India, as of 2016, prevalence of anemia among women of reproductive age was $51.40 \%$; among under five-year-old children was $57.30 \%$; and among non-pregnant women was $51.50 \% .{ }^{(4)}$ There are several potential causes of anemia in the context of Indian population. Development of anemia among under five-year-old children is multi-factorial. Many factors contribute to the occurrence of anemia, including biological, socioeconomic, environmental, health and nutrition. In under five-year-old children, anemia causes depression of the immune system with increased propensity for infection; and reduction of cognitive function, growth and psychomotor development, which leads to difficulties in learning and reduced physical capacity. ${ }^{(3)}$

Anemia affects individuals of both gender and all ages, there is a need for localized and age- and context-specific studies to improve our knowledge of prevalence patterns and associated risk factors of Indian population. The present study was done to determine the prevalence and pattern of anemia in one to five-years old children in a tertiary care teaching hospital.

\section{METHODOLOGY}

This was a prospective observational study, carried out to analyze prevalence and pattern of anemia in under five-yearold children in a tertiary care teaching hospital. The study was conducted in Department of Pediatrics, Sri venkateshwaraa medical college and hospital, Pondicherry, between July 2019 to Dec 2019.112 patients were enrolled for the study.Institutional Ethics Committee approved the study. Patients before enrolling for the study we obtained informed consent.

†www.worldwidejournals.com

\section{INCLUSION CRITERIA}

Children with the both gender in age group of 1-5 years admitted in Pediatric ward with any underlying conditions were included in this study.

\section{EXCLUSION CRITERIA}

Patients who were not investigated with complete hemogram, diagnosed as haemoglobinopathies, who are not willing and on supplements (iron/folic acid) were excluded.

For the diagnosis of anemia, WHO criteria for haemoglobin $\mathrm{Hb}$ ) threshold in different age group were used and according to this haemoglobin threshold is $11.0 \mathrm{gm} / \mathrm{dl}$ for age group of 1 year to 5 years. According to WHO criteria, severity of anemia is classified as: (i) Severe anemia: $\mathrm{Hb}<7.0 \mathrm{gm} / \mathrm{dl}$; (ii) Moderate anemia: $\mathrm{Hb} 7.0-8.9 \mathrm{gm} / \mathrm{dl}$; and (iii) mild anemia: $\mathrm{Hb}$ 9.0-10.9 gm/dl. ${ }^{(5)} \mathrm{A}$ detailed history of the patient was evaluated; a thorough physical examination was carried out and laboratory investigations including complete haemogram and peripheral smear study were done. Important information: (i) child-information: gender, age, height, weight, feeding practices, and any illness 2 weeks prior to survey; and (ii) family-specific-socioeconomic and demographic characteristics of parents, including education level, and marital status. Socioeconomic status of family of children was determined with the help of updated BG Prasad socioeconomic classification scale, which is based on per capita monthly income of the family. ${ }^{(6)}$

Statistical analysis was done using descriptive statistics, Chisquare test for qualitative variables and Student's test for quantitative variables. The $\mathrm{p}$-value $<0.05$ was considered statistically significant for difference and association between variables.

\section{RESULTS:}

Table 1: Age distribution of patients

\begin{tabular}{|l|l|l|}
\hline Age in years & Number of patients & Percentage \\
\hline 1 & 18 & $16.07 \%$ \\
\hline 2 & 14 & $12.5 \%$ \\
\hline 3 & 31 & $27.67 \%$ \\
\hline 4 & 27 & $24.10 \%$ \\
\hline 5 & 22 & $19.64 \%$ \\
\hline Total & 112 & $100 \%$ \\
\hline
\end{tabular}


Table 2: Sex distribution

\begin{tabular}{|c|c|c|}
\hline Sex & Number of patients & Percentage \\
\hline Male & 64 & $57.14 \%$ \\
\hline Female & 48 & $42.85 \%$ \\
\hline Total & 112 & $100 \%$ \\
\hline
\end{tabular}

Table 3: Education of mother

\begin{tabular}{|c|c|c|}
\hline Education of mother & Number of patients & Percentage \\
\hline Illiterate & 22 & $19.64 \%$ \\
\hline Primary & 44 & $39.28 \%$ \\
\hline Secondary or above & 46 & $41.07 \%$ \\
\hline Total & 112 & $100 \%$ \\
\hline
\end{tabular}

Table 4: Socioeconomic distribution

\begin{tabular}{|c|c|c|}
\hline Socioeconomic status & Number of patients & Percentage \\
\hline Class I & 18 & $16.07 \%$ \\
\hline Class II & 14 & $12.5 \%$ \\
\hline Class III & 27 & $24.10 \%$ \\
\hline Class IV & 31 & $27.67 \%$ \\
\hline Class V & 22 & $19.64 \%$ \\
\hline Total & 112 & $100 \%$ \\
\hline
\end{tabular}

Table 5: Disease distribution among patients

\begin{tabular}{|c|c|c|}
\hline Presented condition & Number of patients & Percentage \\
\hline Infectious diseases & 24 & $21.42 \%$ \\
\hline Respiratory & 32 & $28.57 \%$ \\
\hline Gastrointestinal & 26 & $23.21 \%$ \\
\hline Cardiovascular system & 8 & $7.14 \%$ \\
\hline Central nervous system & 11 & $9.82 \%$ \\
\hline Renal & 8 & $7.14 \%$ \\
\hline Others & 3 & $2.67 \%$ \\
\hline Total & 112 & $100 \%$ \\
\hline
\end{tabular}

Table 6: Total number of patients with / without Anaemia

\begin{tabular}{|c|c|c|c|c|c|c|c|}
\hline \multirow[t]{2}{*}{\begin{tabular}{|c|} 
HB \\
distribution
\end{tabular}} & \multicolumn{5}{|c|}{$\begin{array}{l}\text { No of patients with } \\
\text { age distribution }\end{array}$} & \multirow[t]{2}{*}{$\begin{array}{l}\text { Total } \\
\text { (M/F) }\end{array}$} & \multirow[t]{2}{*}{ Percentag } \\
\hline & 1 & 2 & 3 & 4 & 5 & & \\
\hline$\geq 1 \mathrm{lgm} / \mathrm{dl}$ & 8 & 4 & 7 & 6 & 3 & $28(15 / 13)$ & $25 \%$ \\
\hline $9.0-10.9 \mathrm{gm} / \mathrm{d}$ & 7 & 6 & 13 & 11 & 8 & $45(32 / 13)$ & $40.17 \%$ \\
\hline $7.0-8.9 \mathrm{gm} / \mathrm{dl}$ & 3 & 3 & 11 & 9 & 9 & $35(16 / 19)$ & $31.25 \%$ \\
\hline$<7.0 \mathrm{gm} / \mathrm{dl}$ & 0 & 1 & 0 & 1 & 2 & $4(1 / 3)$ & $3.57 \%$ \\
\hline Total & 18 & 14 & 31 & 27 & 22 & $112(64 / 48)$ & $100 \%$ \\
\hline
\end{tabular}

Table 7: Peripheral smear distribution

\begin{tabular}{|c|c|c|}
\hline Smear picture & Number of patients & Percentage \\
\hline Microcytic Hypochromic & 38 & $33.92 \%$ \\
\hline $\begin{array}{c}\text { Macrocytic } \\
\text { Hyperchromic }\end{array}$ & 22 & $19.64 \%$ \\
\hline $\begin{array}{c}\text { Normocytic } \\
\text { normochromic }\end{array}$ & 52 & $46.42 \%$ \\
\hline Total & 112 & $100 \%$ \\
\hline
\end{tabular}

\section{DISCUSSION}

The present study attempted to identify the prevalence, associated factors and pattern of anaemia among children with age between 1 to 5 years in the rural surroundings of Pondicherry, India. Total 112 with one- five years old children admitted to hospital were enrolled in present the study. Boys $64(57.14 \%)$ were more enrolled as compared to girls $(42.85 \%)$. The higher prevalence of admission in male children in the present may be due to the prevailing custom in India of caring more for the male child who were being brought more frequently to hospital for treatment. As per the division according to age groups, children of age group of between 3 and 4 years $(51.67 \%)$ were more admitted as compared age group of 1,2 and 5 years. In the present study, nearly half of the children $(47.32 \%)$ belong to lower socioeconomic (SE) classes (Class IV + Class V) similar study done Singh et al. ${ }^{13}, 28(11.67 \%)$ mothers of anemic children found to be illiterate. More than half of the children (56.67\%) belong to lower socioeconomic (SE) classes [Class IV: 63 $(26.25 \%)+$ Class V: $73(30.42 \%)]$. There are a number of studies, which have shown an association between the socioeconomic status (SES) and the prevalence of anaemia. ${ }^{(7)}$ Similarly in our study almost $50 \%$ of the patients were admitted for respiratory or infection related health issues which are proven fact in children's less than 5 years. Anaemia and infectious diseases, are often co-exist, are the major health burden in developing countries in young children. As like several other studies we also have shown that low parental education levels have been associated with development of anaemia. ${ }^{(8-12)}$ In our study the prevalence of anaemia was $75 \%$ with ranging from mild, moderate and severe. There are various study to support our study that prevalence of anaemia more common in children less than 5 years. ${ }^{(13)}$ Whereas controversy in a study done by S Muthayya et al ${ }^{(15)} 2007$ showed low anaemia prevalence in Bangalore could be due to the impact of school-based intervention programs that have been in place since 2003. The beneficial interactions of deworming and vitamin A supplementation could have widespread implications for current preventive public health initiatives. In our study as like so many studies have concluded microcytic hypochromic followed by macrocytic hyperchromic as the common problems producing anaemia in children below 5 years. Iron deficiency anaemia (IDA) is the commonest nutritional disorder in the world. Around 30\% of the world's population are anaemic, mainly due to iron deficiency. In developing countries like India, this figure is frequently exacerbated by malaria and worm infections. ${ }^{(14)}$ It may be due to poor nutritional status which implies more planning towards prevention in implementation of deworming and nutritional supplementations in children's below 5 years. Important aspectto be noted is there are not in the school going age group. A large portion of iron deficiency is preventable with appropriate and timely intervention.

\section{CONCLUSION}

Anemia in children is a common preventable health issue in under five-years-old children in India. Nutritional deficiency, particularly, iron deficiency is the leading cause of anemia in the present study. This disorder can be primarily prevented by proper nutritional habits deworming and adequate treatment.

\section{REFERENCES}

1. DeMaeyerE,Adiels-TegmanM:Theprevalenceofanemiaintheworld.World Health Stat Q 1985,38:302-316.

2. United Nations Children's Fund/United Nations University/WHO: Iron deficiency anaemia. Assessment, prevention and control. A guide for programme managers (WHO/NHD/01.3). Geneva:World Health Organization; 2001:15-31.

3. Grantham-Mcgregor S, Ani C. A review of studies on the effect of iron deficiency on cognitive development in children.J Nutr. 2001;131:649-68.

4. India-Prevalence of anemia. Indexmundi. Available at:https:// www. indexmundi.com/facts/india/prevalence-of-anemia.

5. Iron deficiency anemia: assessment, prevention and control. A guide for programme managers. Geneva, World Health Organization, 2001 (WHO/ NHD/01.3).

6. Sharma R. Revision of Prasad's social classification and provision of an online tool for real-time updating. South Asian J Cancer. 2013;2:157.

7. Dey S, Gosawmi S, Dey T. Identifying predictors of childhood anaemia in north-east India.J Health Populat Nutr.2013;31 (4):462-70.

8. Hashizume M, Kunii O, Sasaki S, Shimoda T, Wakai S, Mazhitova Z, et al. Anemia and iron deficiency among schoolchildren in the Aral Sea region, Kazakhstan. JTrop Pediatr. 2003;49:172-7.

9. Zhang Q, Li Z, Ananth CV. Prevalence and risk factors for anaemia in pregnant women: a population-based prospective cohort study in China. Paediatr Perinat Epidemiol. 2009;23:282-91.

10. El Hioui M, Ahami AO, Aboussaleh Y, Rusinek S, Dik K, Soualem A, et al. Risk factors of anaemia among rural school children in Kenitra, Morocco. East Afr J Public Health. 2008;5:62-6.

11. Foo LH, Khor GL, Tee ES, Prabakaran D. Iron status and dietary iron intake of adolescents from a rural community in Sabah, Malaysia. Asia Pac J Clin Nutr. 2004;13:48-55

12. Al-Mekhlafi MH, Surin J, Atiya AS, Ariffin WA, Mahdy AK, Abdullah HC. Anaemia and iron deficiency anaemia among aboriginal schoolchildren in rural Peninsular Malaysia: an update on a continuing problem. Trans R Soc Trop Med Hyg. 2008;102:1046-52.

13. Swatantar Singh, Sangeeta Parihar. Prevalence of anemia in under five-yearold children: a hospital-based study. Int J Contemp Pediatr. 2019 Mar;6(2):842-847.

14. Slotzfus RJ, Dreyfuss ML. Nutrition Foundation; Mimeo. Washington, DC: USA INCAG; 1998. Guidelines for the Iron Supplements to prevent and treat irondeficiency anemia: A draft document prepared for the International Nutritional Anemia Consultative Group (INCAG), 17th Jul 1997.

15. S Muthayya, P Thankachanet al,Low anemia prevalence in school-aged children in Bangalore, South India: possible effect of school health mitiatives:European Journal of Clinical Nutrition (2007) 6l, 865-869; doi:10.1038/sj.ejcn. 1602613; published online 24 January 2007 